\title{
LANCANDO-SE NAS MARÉS DO RIO CAETÉ: UM DIA NA JORNADA DE PESCADORAS E PESCADORES ARTESANAIS
}

Maria Eduarda Garcia de Sousa Pereira (D) $\triangle$

Instituto Federal de Educação, Ciência e Tecnologia do Pará I Cametá - PA - Brasil

Roberta Sá Leitão Barboza (D)

Universidade Federal do Pará I Bragança - PA - Brasil

Grazielle Fernanda Gomes (D) $\triangle$

Universidade Federal do Pará I Bragança - PA - Brasil 
A pesca na região amazônica é sinônimo de cultura, conhecimento, segurança alimentar, renda e muita resistência, embora não seja dado o devido valor à atividade e às pessoas nela envolvidas, seja em termos de reconhecimento de seus saberes e seus esforços, seja quanto ao retorno econômico. Esses trabalhadores da pesca, homens ou mulheres, são os principais responsáveis em colocar nas mesas das famílias brasileiras o pescado, um recurso de alto valor e qualidade nutricional.

Nesse contexto, devemos considerar a aridez e as incertezas que permeiam a atividade da pesca, condições que devem ser reconhecidas na gestão da atividade pesqueira, na implementação de políticas públicas voltadas a esses profissionais e no ordenamento pesqueiro. $\mathrm{O}$ estudioso Diegues $(1983,1995,1999)$ aponta elementos fundamentais para que possamos conhecer melhor esses sujeitos, como as práticas e os modos de vida que se constroem em relação a um meio tanto físico quanto socialmente instável e imprevisível. O mar é o espaço de vida mencionado pelo autor, ambiente que é marcado pela instabilidade contínua provocada por fatores meteorológicos e oceanográficos, pela variação e migração das espécies, seus padrões de reprodução, migração, dentre outros. Além dessas, outras marcas são derivadas de temores e medos: acidentes e naufrágios, flutuação dos preços, extrema perecibilidade do pescado, o qual, uma vez capturado, deve ser vendido rapidamente, o que os obriga a acertos particulares de comercialização que, usualmente, lhes são desfavoráveis (Diegues 1999).
Quando esses sujeitos habitam o litoral, há uma relação peculiar com as marés, as quais, de acordo com Nascimento \& Barboza (2020), assumem protagonismos mais significativos do que a própria terra. Nesse cenário, os autores supracitados têm utilizado na academia o termo maretório, construído entre as lideranças extrativistas pesqueiras do litoral para definir essa íntima relação de uso e compreensões do espaço litorâneo que abrange dimensões simbólicas e culturais peculiares. $\mathrm{Na}$ Amazônia, esse espaço abrange, ainda, estuários, riose igarapés.

De modo geral, considerando os ambientes ora descritos, as mulheres ficam mais envolvidas nas atividades realizadas em águas rasas, mangue e em terra. Sob certa medida, a valorização dada aos produtos pesqueiros influencia os tipos de recursos capturados e os ambientes acessados por elas. Na Amazônia oriental, no litoral paraense, por exemplo, as mulheres da Vila do Bonifácio pescam dentro do estuário do rio Caeté, capturando determinadas espécies de peixes costeiros, como a sardinha, o bandeirado, a pescada gó e os bagres, além de crustáceos, como siri e camarão. Já a pesca dos homens, em geral, abrange todo tipo de peixes, costeiros e marinhos, além de camarão e lagosta. A pesca realizada por eles ultrapassa os limites do estuário, alcançando o mar e as espécies-alvo capturadas possuem maior valor comercial. Por outro lado, na comunidade Vila do Treme, como o caranguejo é o recurso de maior valor econômico, sua captura é geralmente realizada pelos homens, cabendo às mulheres a catação da carne durante o beneficiamento (Vieira et al. 2014; Santos et al. 2019). 
Nessa perspectiva de conhecimento, reconhecimento e valorização dos profissionais da pesca, apresentamos um ensaio fotográfico que flagra as peculiaridades e a rotina de trabalho dessas pessoas, em uma cidade no litoral amazônico cuja pesca representa uma atividade de relevante importância social, cultural e econômica (Figuras $1 \mathrm{a}$ 8). Trazemos à luz da lente fotográfica profissionais da pesca do município de Bragança, no estado do Pará, em face a seus meios de produção (barcos e artes de pesca) e “escritórios”, possibilitando aproximar o leitor da realidade da pesca artesanal. Esses pescadores e essas pescadoras têm nas relações com a maré, através do extrativismo, sua base de sustentação socioeconômica.

Os registros fotográficos são frutos da tese da primeira autora, intitulada "Bioecologia e pesca do Camurim Centropomus undecimalis(Centropomidae - Perciformes) na zona costeira amazônica brasileira: contribuição dos atores da pesca para o manejo pesqueiro".

Dito isso, convidamos você, caro leitor, a se lançar nas águas do estuário do rio Caeté e adentrar em um dia da jornada de pescadores e pescadoras artesanais do litoral amazônico!

\section{REFERÊNCIAS}

Diegues, A. C. 1983. Pescadores, camponeses e trabalhadores do mar. São Paulo: Ática. (Ensaios; 94).

Diegues, A. C. 1995. Povos e mares. Por uma socioantropologia marítima. São Paulo: NUPAUB, USP.

Diegues, A. C. 1999. A pesca construindo sociedades. Leituras em antropologia marítima e pesqueira. São Paulo: NUPAUB, USP.

Nascimento, J. R., e R. S. L. Barboza. 2020. Dos seringais aos maretórios: resistências nas Resex-marinhas da Amazônia, in Gestão da água: desafios sociopolíticos e sociotécnicos na Amazônia e no Nordeste Brasileiro. Organizado por P. Teisserenc, M. J. S. A. Teisserenc \& G. M. Rocha. Belém: NUMA/UFPA.

Santos, F. J. S., K. C. A. Silva, B. Bentes, M. E. G. S. Pereira, A. G. C. M. Klautau, e I. H. A. Cintra. 2019. A pesca de lagostas na plataforma continental amazônica. Arquivo de Ciências do Mar 52(2):61-76. DOI: https:// doi.org/10.32360/acmar.v52i2.41666

Vieira, N., D. Siqueira, e D. Paolo. 2014. “O que é de mulher e o que é de homem”: relações de gênero na pesca artesanal, comunidade de Bonifácio, Amazônia Oriental, Brasil. Raízes 34(1):8-23. 


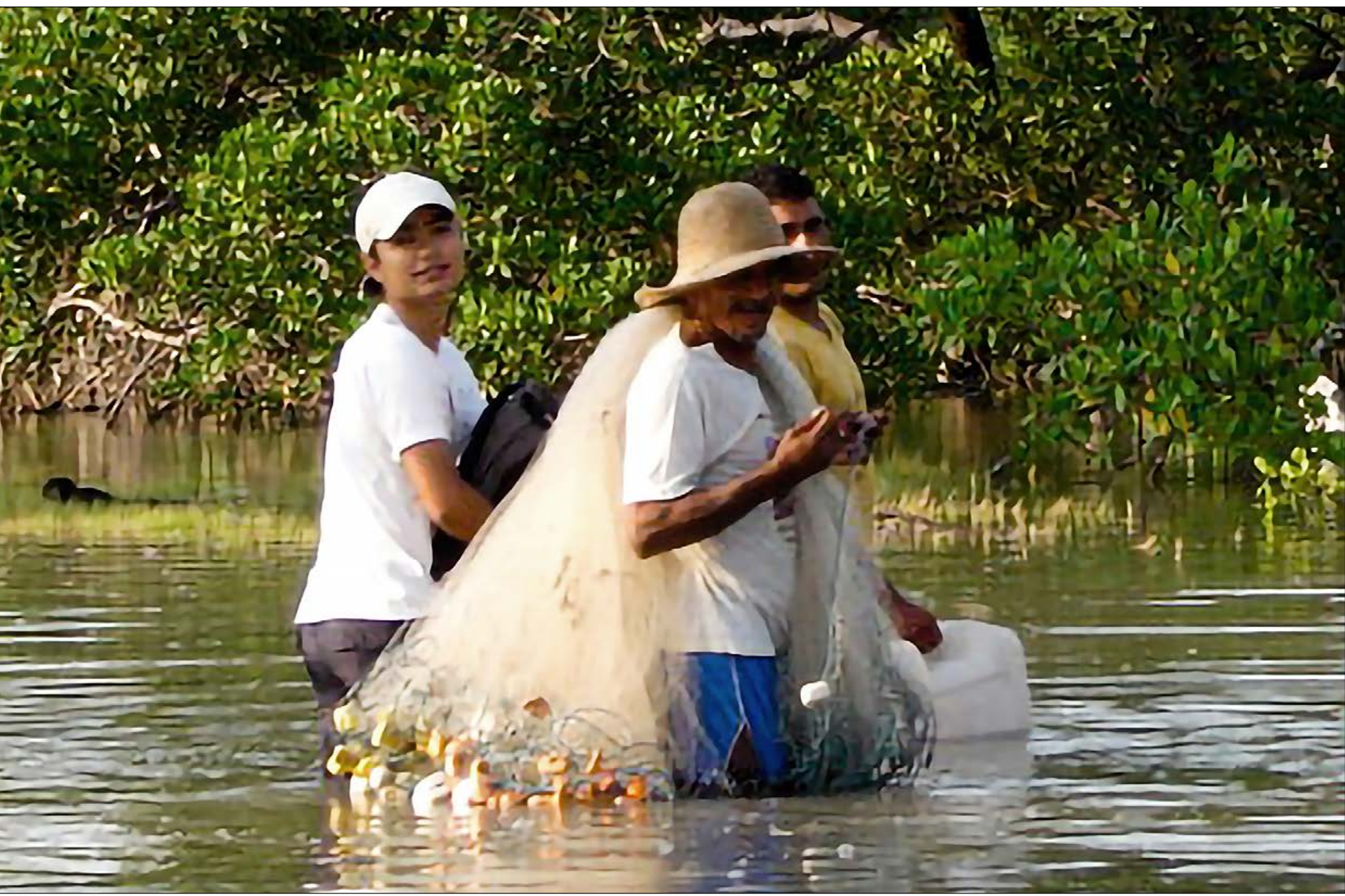

Figura 1 - Caminhando pelas águas até o portinho da vila do Bonifácio. Que Deus proteja os pescadores e pescadoras em mais uma jornada de trabalho! Foto: Maria Eduarda (2018). 


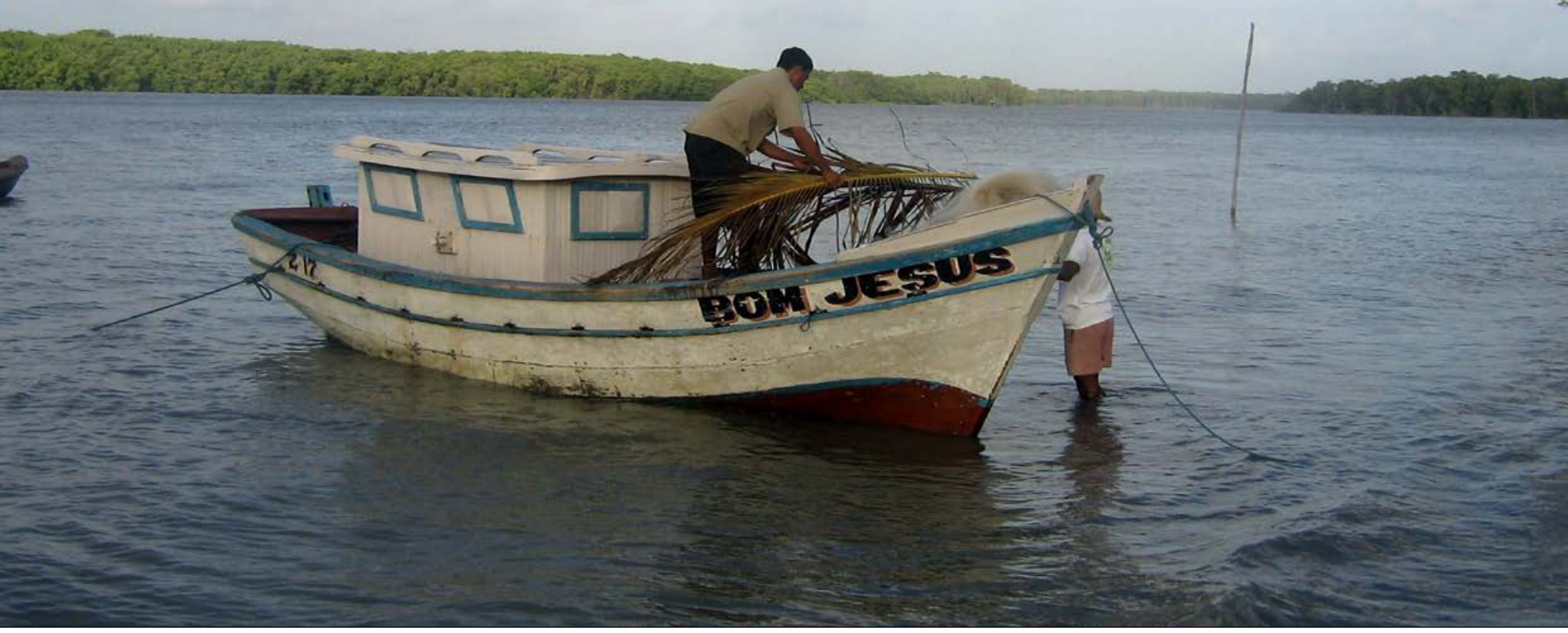

Figura 2 - Hora de organizar a lancha para mais um dia de trabalho. Foto: Maria Eduarda (2018). 


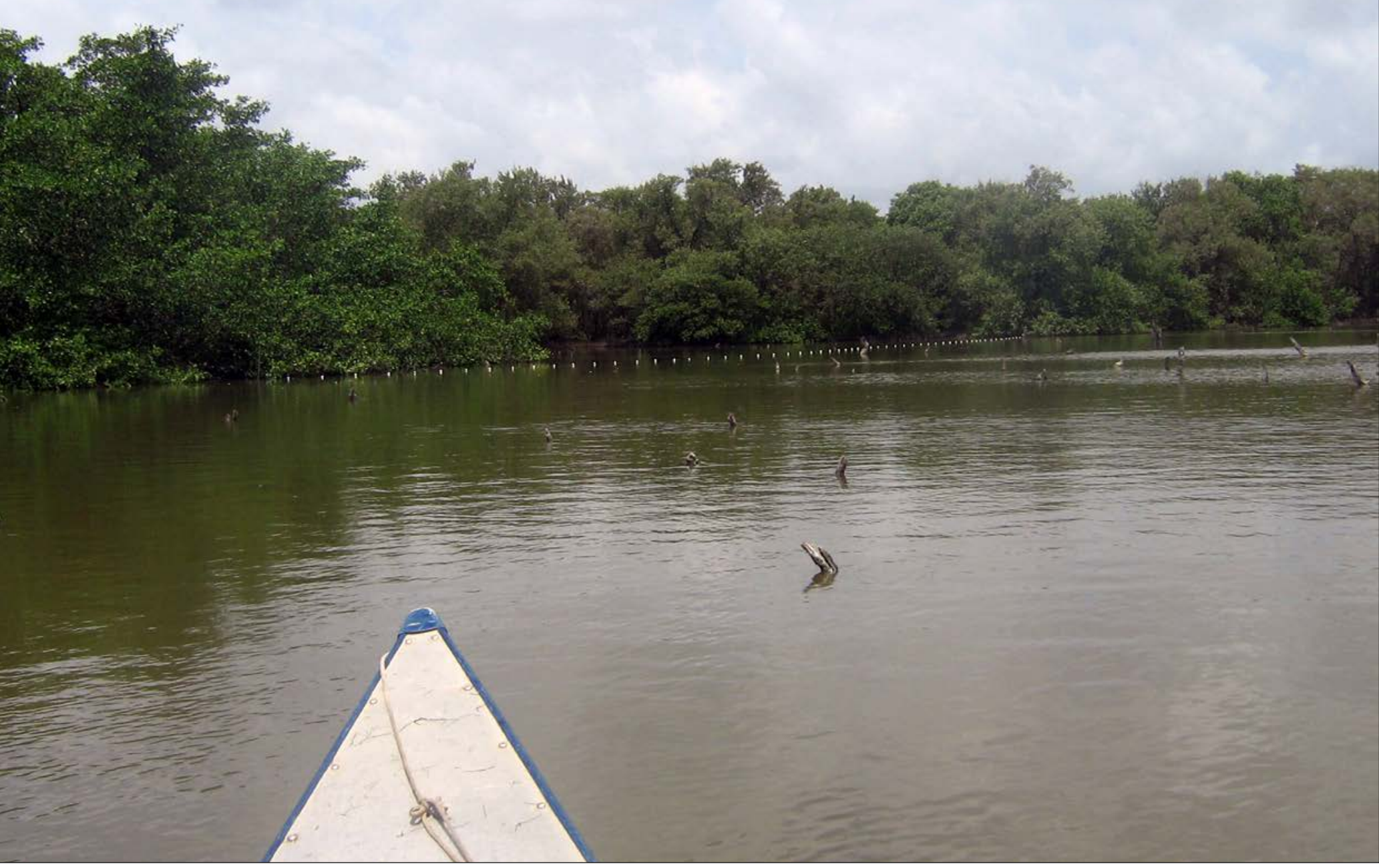

Figura 3 - Navegando em direção aos pesqueiros Foto: Maria Eduarda (2018). 


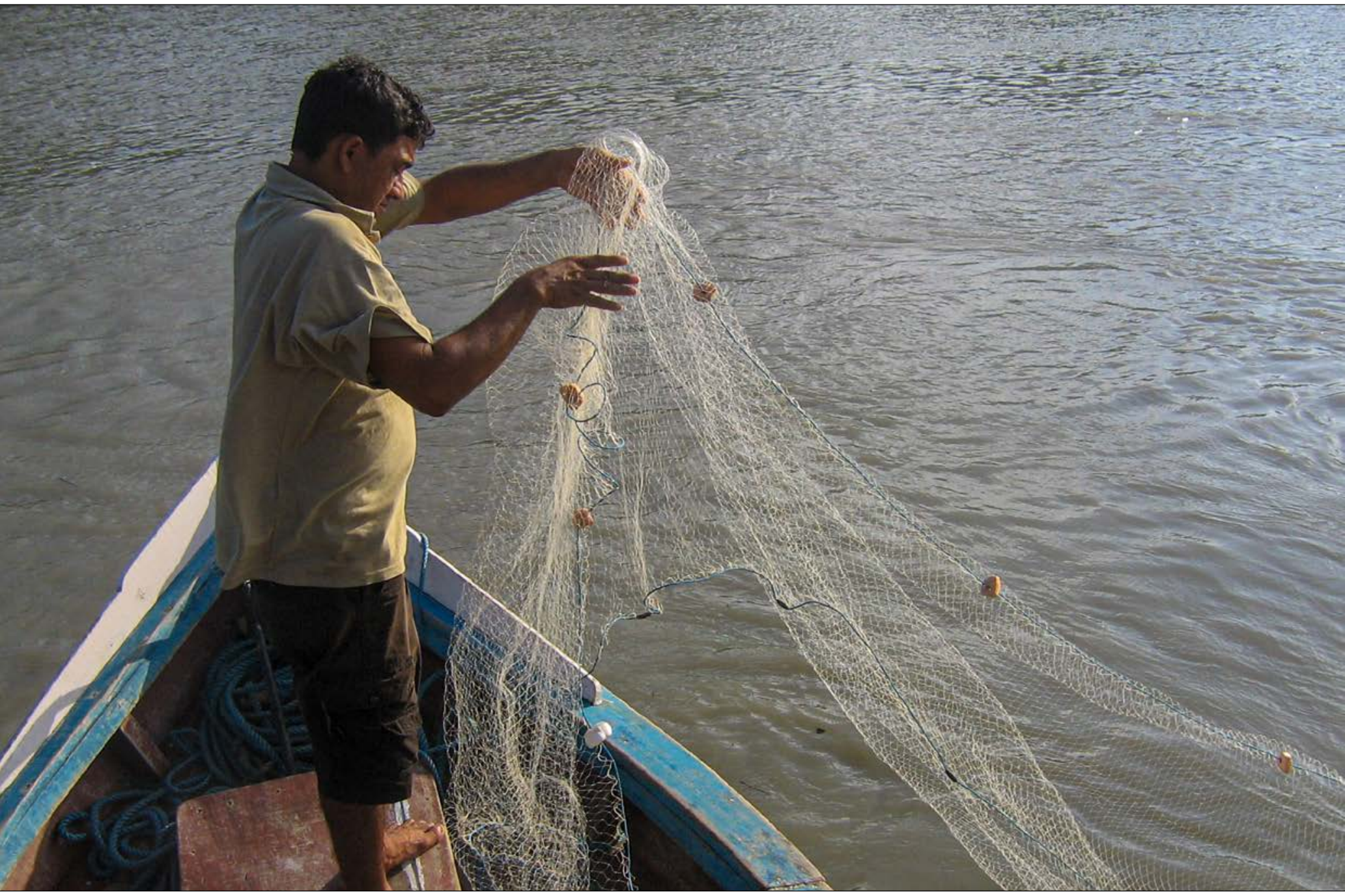

Figura 4 - No pesqueiro, agora, é lançar a rede e aguardar o peixe se emalhar. Foto: Maria Eduarda (2018). 


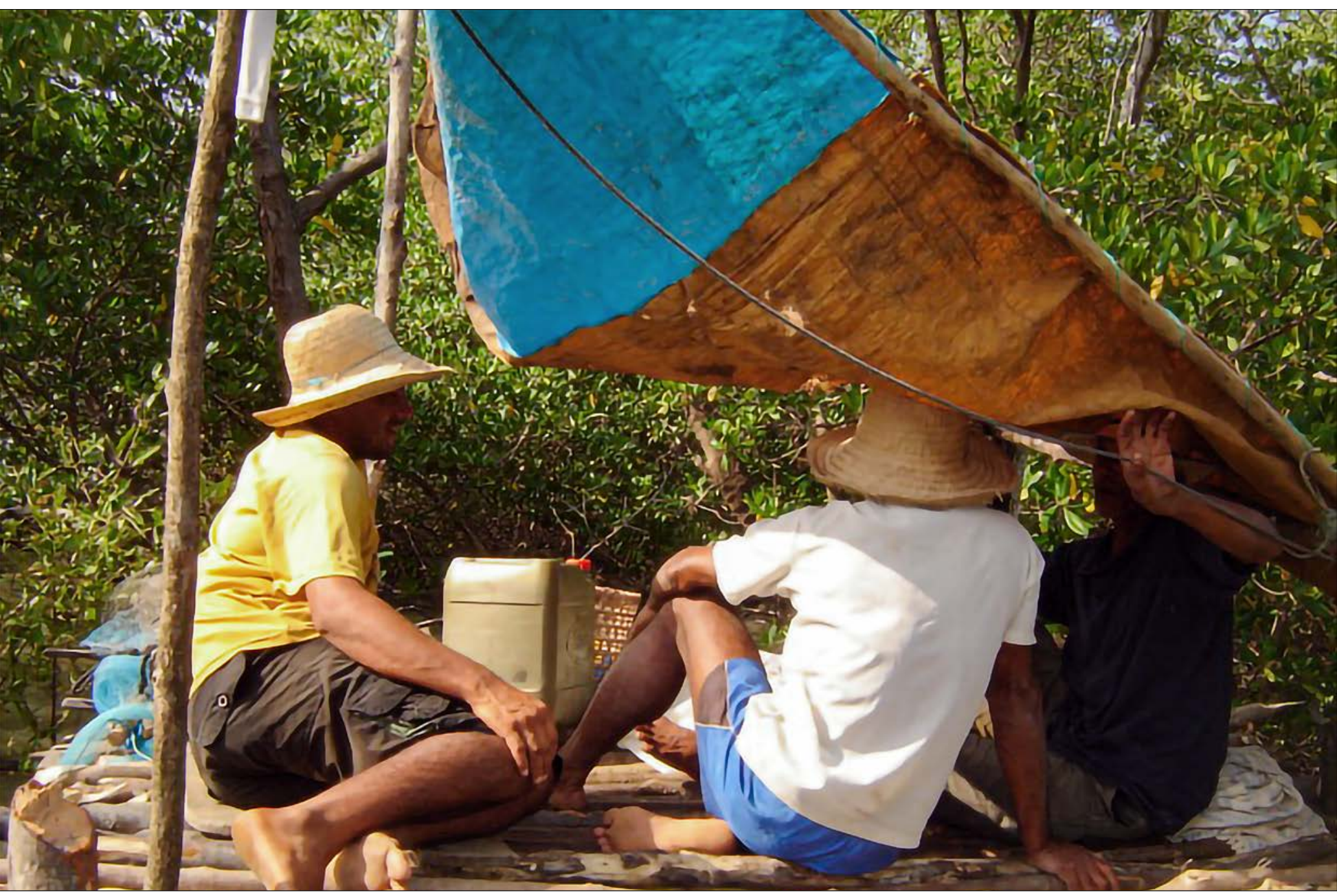

Figura 5 - No rancho, entre um lançamento e o recolhimento da rede, hora de parar para uma prosa, comer o avoado com chibé e esperar... Foto: Maria Eduarda (2018). 


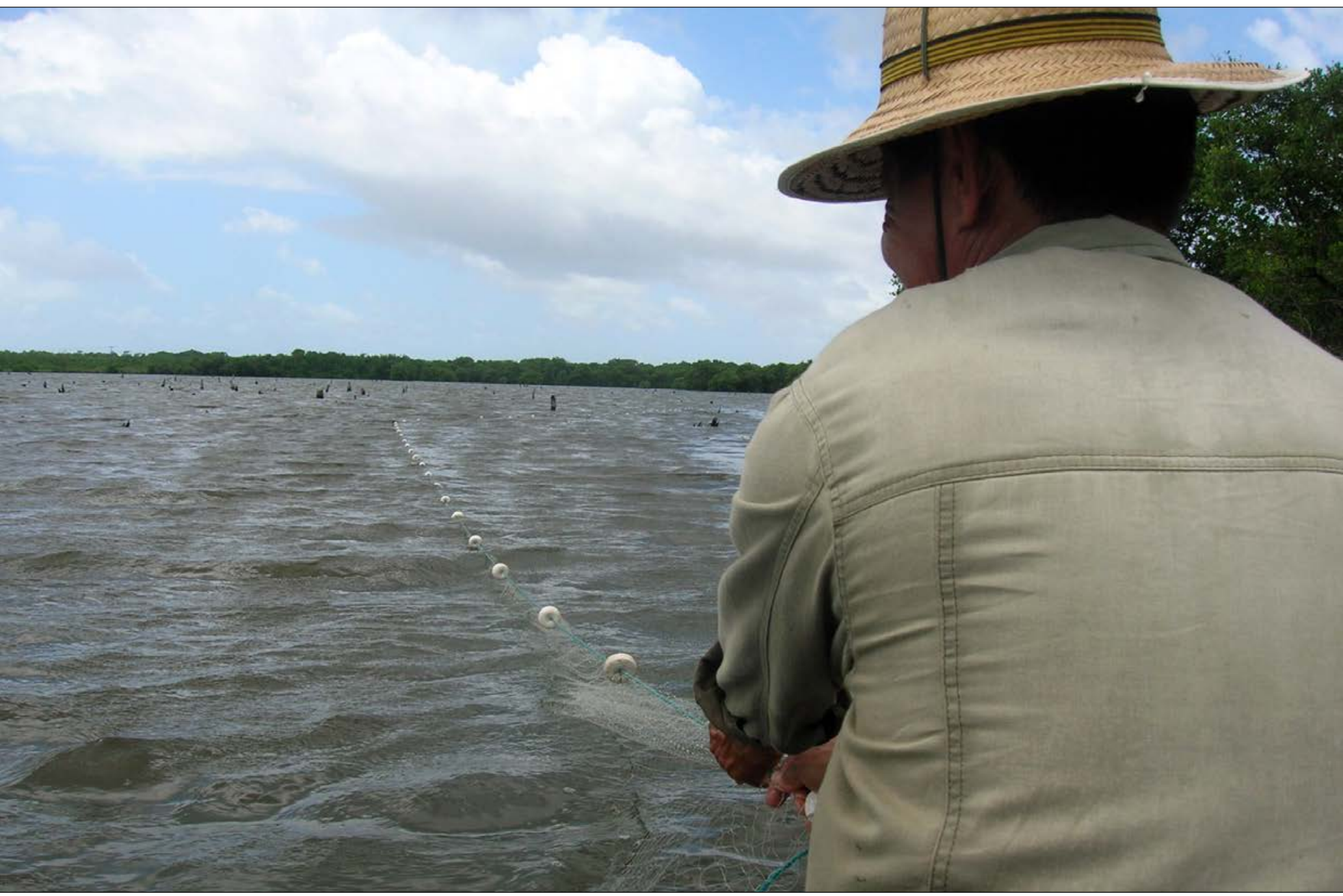

Figura 6 - Hora de fazer vistoria na rede: veio peixe? Foto: Maria Eduarda (2018). 


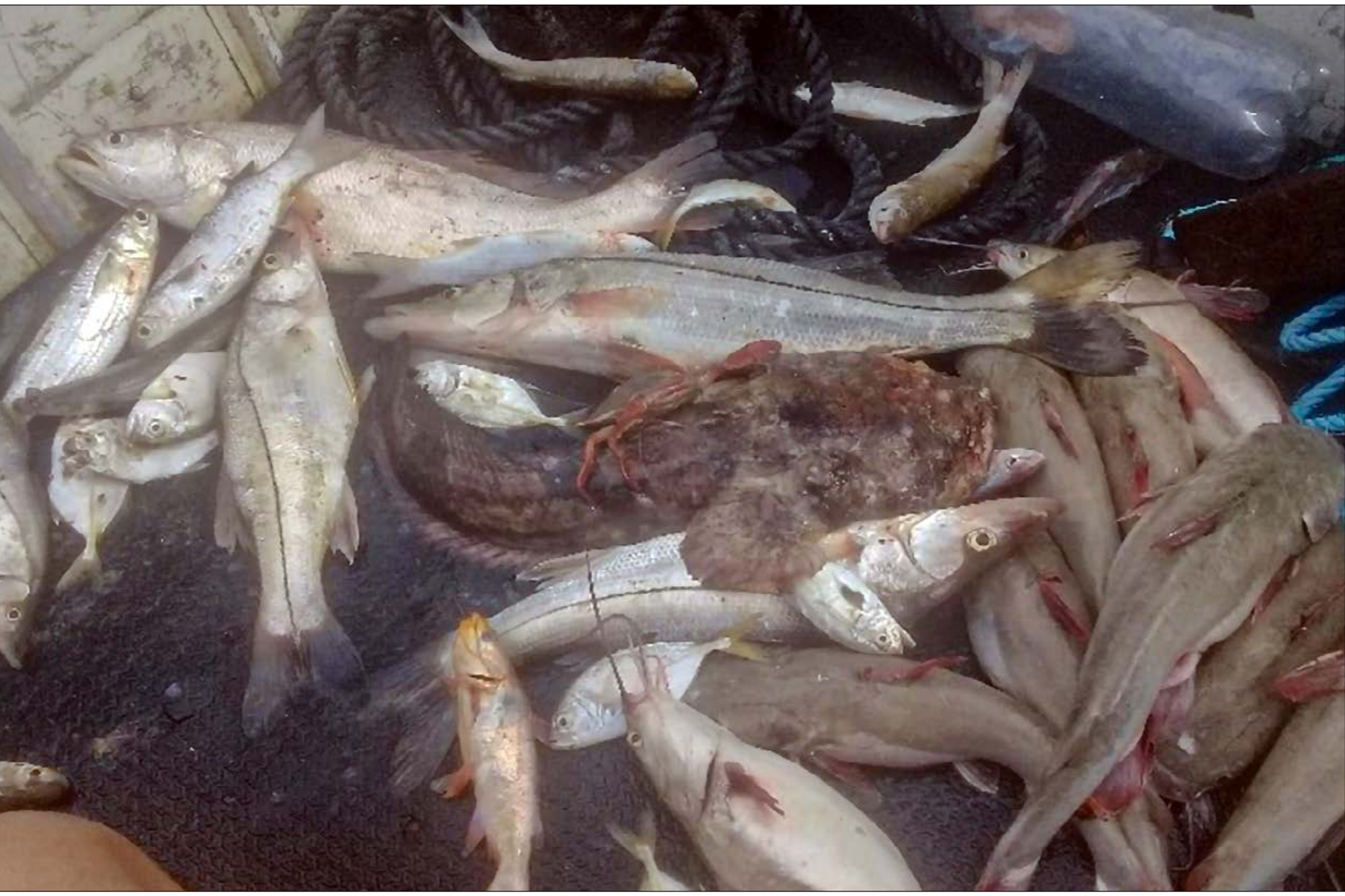

Figura 7 - Veio peixe? Sim, com as bênçãos de São Pedro, a captura de diferentes marcas de peixes: uricica, camurim, bagre do mangue, tainha chata, pacamã e pescada amarela. Foto: Maria Eduarda (2020). 


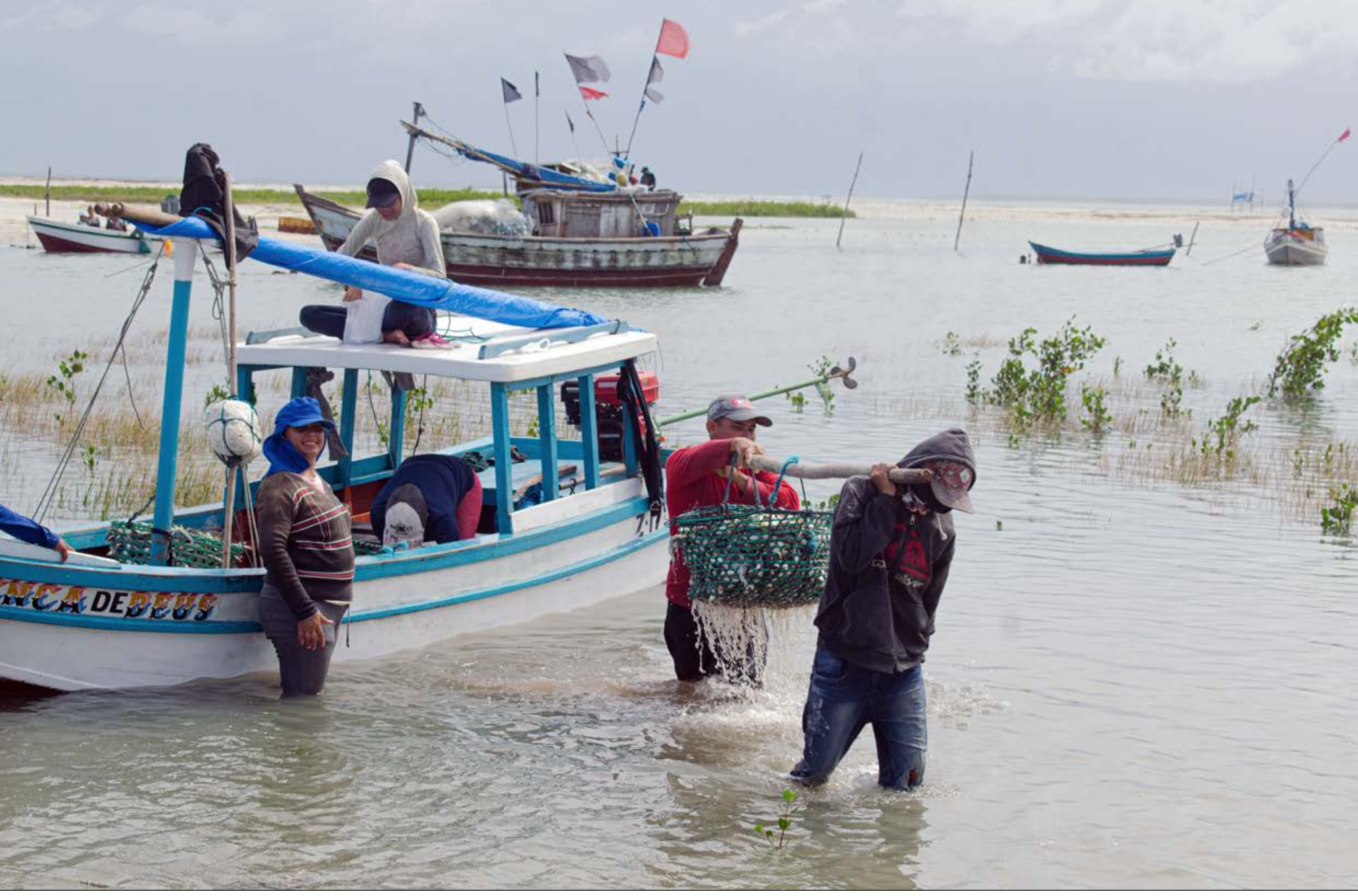

Figura 8 - Em terra, agora, é descarregar a produção e tentar vender o pescado para retornar ao lar. Será que vão pagar o valor merecido? Amanhã, mais um dia para se lançar nas marés do rio Caeté. Foto: Maria Eduarda (2020). 
